\title{
Menace of Road Rage in our valley and Possible Solutions UT-Jammu and Kashmir
}

\author{
“A socio-legal study" by \\ Er. Mubashir jan \\ saekashmir@gmail.com
}

There are really three types of people those who make things happen, those who watch things happen and those who say “what happened".

\section{------Ann Landers}

\section{HIGHLIGHTS:}

1.Unreasonable Offensive Behaviour Of Drivers On Road.

2. Aggressive Driving Being Traffic Wrong Includes Speeding, Tailgating And Abrupt Lane Change Etc.

3. Shouting inappropriately, Rude Gestures.

ABSTRACT: Do you drive with stress and frustration? Do you frequently complain about other drivers or get involved in hostile interactions with other motorists? Are you afraid for your teenage drivers in this climate of highway warfare? We're in the midst of an escalating epidemic of aggressive driving, which eats up 250 billion dollars a year in economic cost and causes the misery associated with 6 million injuries every year.

ROAD RAGE which is unreasonable and offensive behaviour of the drivers has attained the attention of common people. The condition has been so worsened that today, in respect of our roads it is said that "where there is road, there is road rage".

The man behind the wheel "DRIVER" has been an important component to achieve the goal of a developed society which in fact deserves appreciation always.

India being the fifth largest motor vehicle manufacturer in the world has a well connected and co-ordinated transportation system, but with increase in vehicle registrations menace of road violence \& accidents has also increased.

Technology and creation of sustainable cities can be a good option to overcome this menace.

\section{ROAD RAGE: Concept And Meaning:}

The phrase "ROAD RAGE" was coined by media during 1980's in U.S.A and later came into use in Australia, Great Britain and other countries. It goes back ultimately to Latin word rabere to Rome which is also the source of rabies and rabid meaning madly violent or "furious".

Encyclopaedia of murder \& violent crimes at page 485 defines 'Road Rage' as random acts of violence or aggressive behaviour carried out by frustrated or over stressed drivers.

Concise Oxford English dictionary defines Road Rage as 'Violent Anger' arising from conflict with the driver of another motor vehicle.

Sometimes the term Road Rage and aggressive driving are used interchangeably but these terms are not synonymous. Aggressive driving being traffic wrong includes speeding, Tailgating and abrupt lane change etc. having risk to the people and property and on the other hand Road Rage is expression of rude gestures, uncontrolled frustration, imitation and anger resulting in violence varying from verbal abuse to physical assault including serious injuries and deaths. Rage cannot escalate unless the anger level passes the point of control.

In simple terms the road rage is a social problem related to motor vehicles driving having multiple adverse effects on the victim as well as on the society. It is a criminal behaviour and is directly related to individual psychology upbringing etc.

\section{COMMON CAUSES OF ROAD RAGE ARE:-}

1.LACK OF EDUCATION:Lack of Driver training,Rude Gestures,Abusing etc

2. Flashing of high beams.

3. Honking horns. 
4. Shouting inappropriately, Rude Gestures.

5.Halting of vehicles on roads causing impediments to free flow of traffic.

6. Wrong overtaking.

7.Alcohol consumption.

8.Tailgating.

9.Turning without use of indicators.

10. Traffic Jams.\& many more..

\section{CHECKLIST: YOUR RANGE OF HOSTILITY:}

The following twenty steps are arranged along a continuum of escalating degrees of hostility, beginning with relatively milder forms of aggressiveness (step 1) and going all the way to extreme violence (step 20). How far down the uncivilized path do you allow yourself to go? The majority of drivers we tested go as far as step 13.

1. Mentally condemning another driver.

2. Verbally denigrating another driver to passengers in your vehicle.

3. Closing ranks to deny someone entry into your lane because you're frustrated or upset.

4. Giving another driver the "stink eye" to show your disapproval.

5. Speeding past another car or revving the engine as a sign of protest.

6. Preventing another driver from passing because you're mad.

7. Tailgating to pressure a driver to go faster or get out of the way.

8. Fantasizing physical violence against another driver.

9. Honking or yelling at someone through the window to indicate displeasure

10. Making a visible obscene gesture at another driver.

11. Using your car to retaliate by making sudden, threatening maneuvers

12. Pursuing another car because of a provocation or insult.

13. Getting out of the car and engaging in a verbal dispute on a street or parking lot.

14. Carrying a weapon in the car in case you decide to use it in a driving incident

15. Deliberately bumping or ramming another car in anger.

16. Trying to run another car off the road to punish the driver

17. Getting out of the car and beating or battering someone as a result of a road exchange.

18. Trying to run someone down whose actions angered you.

19. Shooting at another car (USUALLY HAPPENS IN WESTERN WORLD).

20. Killing someone.

How far down did you go on the continuum? The checklist is divided into five equal zones of intensity of aggressiveness.

Unfriendly Zone: Items 1 to 3 -- mental and verbal acts of unkindness toward other drivers

Hostile Zone: Items 4 to 7 -- visibly communicating displeasure or resentment with the desire to punish or retaliate

Violent Zone: Items 8 to 11 -- carrying out an act of hostility either in fantasy or in deed

Lesser Mayhem Zone: Items 12 to 16 -- epic road rage contained within personal limits

Major Mayhem Zone: Items 17 to 20 -- unrestrained epic road rage; the stuff of violent media headlines.

Traffic psychology educators Dr. Leon James and Dr. Diane Nahl trace the aggressive driving problem to its roots in childhood when child passengers imbibe their parents' aggressiveness towards other motorists and their cynicism towards regulations and the law. By the time teenagers begin to drive they've been exposed to years of media portrayals of the fun and excitement of aggressive driving with no serious consequences. The authors argue that road rage and aggressive driving are common traffic emotions experienced by the vast majority of drivers. 
Summary:J\&k has almost 18 lacs vehicles registered ,According to MORTH report (Transport Research Wing)- 2017, $40.6 \%$ fatalities took place in urban areas \& $59.4 \%$ in rural areas. The entire development of a city, town or a village, nay the whole country depends on the type of transport that is available for men and materials with an eye on effective land usage.30\% Road Traffic fatalities of two wheelers specifically in J\&K are attributed to Road Rage.

Housing and Urban Development Department is the main Actor to ascertain Sustainable Transportation of men \& Materials .besides other actors like PWD/TRANSPORT /HEALTH/EDUCATION DEPARTMENT.

The community pays for good roads whether it has them or not. If the economy can afford a modern system like a bullet train, an underground railway, metro etc or modern cars in large numbers, we must have them but the first thing however must come first i.e. the mobility for " POOR". We should quantify the requirement of urban buses at the aggregate level for various population sizes of urban agglomerations.

As per research we need 600 buses (52 seater) for 1 lac population and for Jammu \& Kashmir valley to mobilize people safely with a reliable, safe, affordable transport system we need 35 lac seats (Service Mix of vehs) with established bus depots, to cater to the travel Demand, here JKSRTC an STU./Private Players can play a vital role if it revives it Depots across UT of JANDK.

Government has already initiated an Incentive based Policy to augument Busses/Minibusses replacing old ones.

TRAFFIC SCENE:- Lack of reliable Public Transport especially MIDI \& MINI BUSSES as envisaged under Automotive Industry Standards-AIS-052.

.Pedestrians are pushed to carriage ways as pavements are occupied by hawkers ,mostly we don't have them.

.Mixed traffic shares the SCARCE ROAD.

.Growth of personalised modes of transport 2 wheelers, cars etc.

.Lack of public transport (though $70 \%$ people still use public transport in $\mathrm{j} \& \mathrm{k}$, they board minibuses which have squeezed seating space.

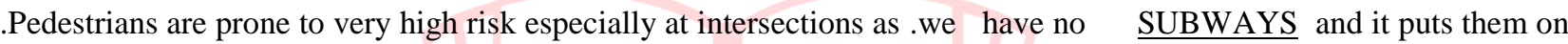
risk.

.Lot of pollution \& noise ,Adetailed Study on evidence data can guide us in a better way to formulate a long term Transport Policy.

\section{CONGESTION:-}

The Motor Vehicles are back bone of our development. On one hand have facilitated the easy, convenient, \& fast transportation of passengers \& goods but on the other hand have become a potential cause of violence on the roads with Intolerable Traffic Snarls/congestion.

ROAD RAGE which is unreasonable and offensive behaviour of the drivers has attained the attention of common people. The condition has been so worsened that today, in respect of our roads it is said that "where there is road, there is road rage".

The man behind the wheel "DRIVER" has been an important component to achieve the goal of a developed society which in fact deserves appreciation always.

India being the fifth largest motor vehicle manufacturer in the world has a well connected and co-ordinated transportation system, but with increase in vehicle registrations menace of road violence \& accidents has also increased.

We should not only have stringent laws to curb this menace, we should also create infrastructure for Roads \& for quality driving institutions. In this Regard (MVD) has taken a lead, Traffic Police are also on toes to regulate traffic.We Should Conduct A Study to overcome this menace.

Intelligent Transportation Systems and Photo Enforcement, Red light runners and speeders can be captured on camera and it can act as a deterrence. This method makes it possible to detect traffic violators without the physical presence of a law enforcement officer.

RECOMMENDATIONS:-we all should follow the Motor Vehicles Driviving Regulations, 2017 ,it precisely has reflected duties of Drivers and Riders ,Lane Traffic, Right of way ,Precautions to be taken at Intersections, Roundabouts, Traffic control $\underline{\text { Signals..... }}$

During Covid -19 Pandemic Rescheduling of timings /closure of Establishments have made a great impact on traffic congestion we see clean cities as Air quality has improved a lot.Is corona an opportunity to Rethink our Priorities.? 


\section{Lets Ponder!}

1.Driving is not a competition rather it is a skill based art to be safe. keep safe distance .

2.Drivers must ride motor vehicles stress free and with a cool mind with proper attention on road.

3.We should try to get up early, pray and meditate to keep ourselves fresh, focussed having a blissful feeling whole day.

4.Faith in God is important.

5.Undue worries increase our sufferings while we feel insecure and disturbed rather we should be thankful always to Almighty and believe in Decree/Destiny.

6.We should often breathe and relax so that the mind becomes calm and very subtle.

7.We should drink plenty of water to keep ourselves hydrated, exercise well or walk often to improve our health which stimulates our mind and soul.

8.Live your life, smile often.

9.Be aware of your thoughts it can discipline your life as we are not 'Machines or Robots'.we are Prone to mistakes.

10Transform yourself for better.

11.Greet co-drivers or at least smile it will surely make a difference, we as rational human beings respond.

12.Stop conflicts going on in your sub conscious mind.

13.Skip some time and relax.

14.Trust your confidence and try to motivate others for creating a better and value based society.

\section{LOVE BEGETS LOVE}

"Let's develop sustainable infrastructure which include improvement in mobility making it a world class destination with an eye on effective land use planning and Air pollution.

Er. Mubashir Jan

saekashmir@gmail.com

References:

1.Ministry of Road Transport,GOI.(morth.nic.in)

2.Motor Vehicles Department J\&K(jaktrans.nic.in)

3. Road Rage and Aggressive Driving: Steering Clear of Highway Warfare-Dr leon james et al.

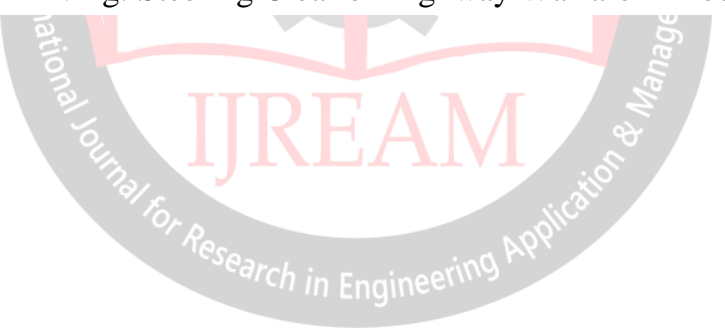

